\title{
Hypokalaemia and ventricular fibrillation in acute myocardial infarction
}

\author{
J E NORDREHAUG, G VON DER LIPPE \\ From the Department of Medicine, Diakonissehjemmets Sykehus, Haraldsplass, Bergen, Norway
}

SUMMARY Serum potassium concentrations obtained on admission to hospital were inversely related to the incidence of ventricular fibrillation in 289 women and 785 men with acute myocardial infarction, 92 of whom developed ventricular fibrillation. Hypokalaemia (serum potassium concentration $\leqslant 3.5 \mathrm{mmol} / \mathrm{l}$ ) was found in 122 patients $(11.4 \%)$. The incidence of ventricular fibrillation was significantly greater in patients with hypokalaemia compared with those classified as normokalaemic (serum potassium concentration $\geqslant 3.6 \mathrm{mmol} / \mathrm{l})(17.2 \% v 7.4 \%)$. The increased risk of ventricular fibrillation in the hypokalaemic group was about the same for women and men. While they were in hospital patients with hypokalaemia developed ventricular fibrillation significantly earlier than did normokalaemic patients (median 0.3 hours $v 7$ hours). Hypokalaemia was more common in women (17.3\%) than in men $(9.2 \%)$, and $55 \%$ of the hypokalaemic patients had been treated with diuretics before admission compared with $22 \%$ of the normokalaemic group. Hypokalaemia on admission to hospital predicts an increased likelihood and early occurrence of ventricular fibrillation in patients with acute myocardial infarction.

Hypokalaemia has been associated with an increased incidence of ventricular fibrillation in patients with acute myocardial infarction. Most studies have included patients with mild hypokalaemia: serum potassium concentration $<3.5 \mathrm{mmol} / \mathrm{1}^{1-3}$ or $<3.6$ $\mathrm{mmol} / 1 .^{4-6}$

The association of ventricular fibrillation and low serum potassium concentration, however, has been shown only for subgroups of patients with ventricular fibrillation over certain periods in hospital,,$^{2-4}$ and for subgroups based on serum potassium concentrations. ${ }^{4}$ The allocation of patients to hypokalaemic and normokalaemic groups has been based on potassium values obtained around the time of the ventricular fibrillation compared with potassium values obtained on admission for patients without ventricular fibrillation. ${ }^{25}$ Some studies have been too small to permit conclusions. ${ }^{36}$ Others have reported an association between diuretic treatment and hypokalaemia in patients with acute myocardial infarction and ventricular fibrillation, but they have not given figures for the incidence of ventricular fibrillation in hypokalaemic patients. ${ }^{1}$ Differences between patients for other possible determinants of ventricular fibrillation apart from serum potassium concentrations have

Accepted for publication 12 July 1983 not been investigated.

The objective of our study was to relate the potassium concentrations in patients with acute myocardial infarction at the time of their admission to hospital to the incidence and prognosis of ventricular fibrillation during their stay there.

\section{Patients and methods}

Patients with acute myocardial infarction admitted to five of the $\mathbf{2 0}$ hospitals in the Norwegian multicentre study on timolol after acute myocardial infarction' were eligible for inclusion in the study. One thousand and seventy-four patients comprising both those included in and excluded from the timolol trial ${ }^{7}$ were studied, and the qualifying criteria for acute myocardial infarction, mortality classification, and other clinical and laboratory procedures were as previously described. ${ }^{7}$ The patients were allocated to six groups according to serum potassium concentration on admission.

All patients had continuous electrocardiographic monitoring for the first two days or longer if indicated. The presence of ventricular fibrillation was determined either by observation of it on an oscilloscope or by an automatically recorded rhythm strips, or both. All patients with ventricular fibrillation had 
clinical signs, and resuscitation with a thump on the chest and/or direct current conversion and/or external cardiac massage and artificial respiration or combinations of these had to be carried out on all patients. Four patients were found dead in bed during their stay in hospital (one hypokalaemic and three normokalaemic patients) and they were not included in the group of patients with ventricular fibrillation.

Only the first episode of ventricular fibrillation in each patient was considered. Both primary and secondary (complicating) ventricular fibrillation ${ }^{8}$ were accepted but not ventricular fibrillation resulting from terminal arrhythmias produced by drugs during resuscitation. Twelve patients had ventricular fibrillation on admission, and all had received external cardiac massage and artificial ventilation for one half to 20 minutes before admission. Drugs or direct current conversion were not used during resuscitation before admission to hospital.

Blood samples for estimation of serum potassium concentration were taken on admission, centrifuged immediately, and analysed by flame photometry. Only the initial value was used in the study. Serum potassium and arterial acid-base analyses were performed simultaneously for 12 patients who had ventricular fibrillation on admission and in whom blood for serum potassium analysis was drawn after the onset of ventricular fibrillation. None of these were given diuretics between the onset of ventricular fibrillation and taking the blood sample.

Prophylactic antiarrhythmic treatment was not used. No patients were given intravenous potassium. A chest radiograph in the standing position was taken routinely at the end of the first week in hospital.

Hypokalaemia was defined as a serum potassium concentration $\leqslant 3.5 \mathrm{mmol} / 1$ and hyperkalaemia as serum potassium $\geqslant 5.2 \mathrm{mmol} / /$. The figure shows further divisions into subgroups. For statistical analysis the hyperkalaemic patients were included in the normokalemic group.

\section{STATISTICAL ANALYSIS}

Statistical calculations were two sided, and $p$ values below 0.05 were considered significant. The grouping of the potassium values into six groups permitted this variable to be considered as an ordered category variable. Potassium values in the presence or absence of ventricular fibrillation, with different drug treatments, and in other events were compared using a general linear model for a weighted sum of the frequencies of the various response categories (potassium groups). ${ }^{10}$ Groups with low potassium concentrations were compared with groups with medium or high potassium values using a contrast statement appropriate for the above model.

Other contingency tables were analysed using

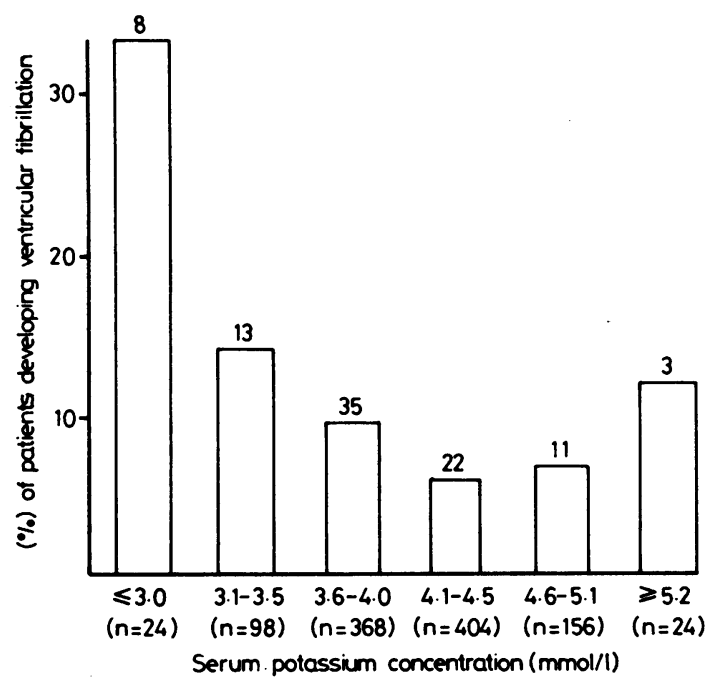

Fig. Number and percentage of patients developing ventricular fibrillation in relation to senum potassiven concentration. Of the 122 patients with hypokalaemia $17 \cdot 2 \%$ developed ventricular fibrillation compared with $7.5 \%$ of the 952 normokalaemic patients $(p<0.01)$.

Fisher's exact test or an exact rank sum test for a $2 \times \mathbf{N}$ contingency table, as appropriate. Continuous variables-for example, blood pressure and agewere analysed using an analysis of variance of the overall relative ranks of the observations.

\section{Results}

Ventricular fibrillation occurred in 92 of the 1074 patients with acute myocardial infarction. The incidence of ventricular fibrillation was significantly higher in hypokalaemic (17.2\%) compared with normokalaemic $(7.5 \%)$ patients $(p<0.01)$ (Fig). The lowest incidence of ventricular fibrillation $(5.9 \%)$ was in the groups with serum potassium concentrations of 4.1-5.1 mmol/1. Below this there was an inverse relation between potassium concentration and frequency of ventricular fibrillation, and at potassium values of $\leqslant 3.0 \mathrm{mmol} / \mathrm{l} 33 \%$ of the hypokalaemic patients developed ventricular fibrillation.

The incidence of ventricular fibrillation in the hypokalaemic group and the normokalaemic group was about the same for women and men. Nine of the 50 women in the hypokalaemic group (18\%) developed ventricular fibrillation compared with 15 of $239(6.3 \%)$ in the normokalaemic group, a significant difference $(p<0.05)$. Similarly, 12 of the 72 men with hypokalaemia $(16.7 \%)$ developed ventricular fibrillation compared with 56 of $713(7.9 \%)$ men with normokalaemia $(p<0.05)$. Hypokalaemia was, however, 
Table 1 Number and percentage of hypokalaemic and normokalaemic patients with acute myocardial infarction

\begin{tabular}{|c|c|c|c|}
\hline Group & $\begin{array}{l}\text { Total No } \\
\text { of patients }\end{array}$ & $\begin{array}{l}\text { No }(\%) \text { of patients } \\
\text { with serum } \\
\text { potassium } \\
\leqslant 3.5 \mathrm{mmol} / \mathrm{l}\end{array}$ & $\begin{array}{l}\text { No (\%) of patients } \\
\text { with serum } \\
\text { potassium } \\
\geqslant 3.6 \mathrm{mmol} / \mathrm{m}\end{array}$ \\
\hline $\begin{array}{l}\text { All patients } \\
\text { Women } \\
\text { Men }\end{array}$ & $\begin{array}{r}1074 \\
289 \\
785\end{array}$ & $\begin{array}{c}122(11 \cdot 4) \\
50(17 \cdot 3)^{\star} \\
72(9 \cdot 2)\end{array}$ & $\begin{array}{l}952(88.6) \\
239(82.7) \\
713(90.8)\end{array}$ \\
\hline
\end{tabular}

${ }^{\star} \mathrm{p}<0.01$.

more common in women than in men (Table 1).

The mean age for women with ventricular fibrillation was 63.5 years $(61.9$ and 64.5 for those with low and normal potassium values respectively) and the mean age of men with ventricular fibrillation was 63.9 years (65.4 and 63.5 respectively). For all 1074 patients women were significantly older than men, with a mean age of 64.8 compared with 62.0 years $(p<0.01)$. Table 2 compares the hypokalaemic and normokalaemic patients with ventricular fibrillation for clinical and $x$ ray film characteristics. There were no significant differences between the groups apart from clinical and radiological signs of lung congestion, which were more common among normokalaemic patients. Similar percentages of patients in each potassium group were either too ill or dead before a chest $x$ ray film in the standing position could be taken.

Frusemide was the drug of choice in all five hospitals for treating initial heart failure: mean daily dosage during the first week was $52.9 \mathrm{mg}$ in the hypokalaemic and $83.2 \mathrm{mg}$ in the normokalaemic group. There were no significant differences between low and normal potassium groups for mean peak concentration of serum aspartate aminotransferase and systolic and diastolic blood pressures on admission.

Patients with hypokalaemia developed ventricular fibrillation earlier than normokalaemic patients; 16 of 21 hypokalaemic patients (76\%) developed ventricular fibrillation within two hours of admission compared with 28 of 71 normokalaemic patients (39\%). Between two and 12 hours after admission three of 21 (14\%) hypokalaemic patients and 13 of 71 (18\%) normokalaemic patients developed ventricular fibrillation, and more than 12 hours after admission the corresponding figures were two of $21(10 \%)$ and 30 of 71 (42\%) patients. The median time from admission to the occurrence of ventricular fibrillation in the low and normal potassium groups was 0.3 hours and 7 hours respectively $(p<0.01)$. The mean time from the onset of acute myocardial infarction to admission was 3 hours and 3.8 hours in the hypokalaemic and normokalaemic groups, with a median time of 1 hour for both groups.

Table 3 shows mortality during the first three months after the infarction for patients with ventricular fibrillation. Thirty-three per cent in the hypokalaemic group and $44 \%$ in the normokalaemic group died. Women had a higher mortality than men, but the difference was not significant. Total cardiac death within 48 hours of admission for patients with ventricular fibrillation was $5 \%$ and $11 \%$ in the hypokalaemic and normokalaemic groups respectively and sudden cardiac death within 48 hours of admission was $0 v 10 \%$ respectively (NS).

Table 2 Characteristics of 92 patients with ventricular fibrillation according to serum potassium concentration

\begin{tabular}{|c|c|c|c|}
\hline Characteristics & $\begin{array}{l}\% \text { patients with } \\
\text { serum potassium } \\
\leqslant 3.5 \text { mmol/l } \\
(n=21)\end{array}$ & $\begin{array}{l}\% \text { patients with } \\
\text { serum potassium } \\
\geqslant 3.6 \mathrm{mmol} / \mathrm{l} \\
(n=71)\end{array}$ & $p$ \\
\hline \multicolumn{4}{|l|}{ Clinical history } \\
\hline Previous infarction & 19 & 32 & \\
\hline Angina & 43 & 45 & \\
\hline Treatment for hypertension other than by diuretics & 14 & 11 & \\
\hline Diuretics & 38 & 24 & \\
\hline Digitalis & 10 & 23 & \\
\hline Antiarrhythmics & 0 & 6 & \\
\hline Beta blockers & 19 & 20 & \\
\hline \multicolumn{4}{|l|}{ Site of infarct } \\
\hline Anterior & 57 & 48 & \\
\hline Inferior & 38 & 42 & \\
\hline Other or uncertain. & 5 & 10 & \\
\hline Pathological $Q$ wave in electrocardiogram & 86 & 68 & \\
\hline \multicolumn{4}{|l|}{ Treatment with frusemide during first week after } \\
\hline $\begin{array}{l}\text { admission } \\
X \text { ray film and clinical findings }\end{array}$ & 48 & $X$ ray film and clinical findings & \\
\hline $\begin{array}{l}X \text { ray nim and cinncal nnaings } \\
\text { Enlarged heart ( } x \text { ray film) }\end{array}$ & 29 & 32 & \\
\hline Lung congestion ( $x$ ray film) & 5 & 21 & $<0.05$ \\
\hline$X$ ray not done & 19 & 24 & \\
\hline Pulmonary rales on admission & 0 & 35 & $<0.01$ \\
\hline Systolic blood pressure $\leqslant 100 \mathrm{~mm} \mathrm{Hg}$ & 43,75 & 48 & \\
\hline Mean age (years) (range) & $63 \cdot 7(44-75)$ & $63.5(47-75)$ & \\
\hline
\end{tabular}


Table 3 Number of deaths within three months among patients with ventricular fibrillation

\begin{tabular}{|c|c|c|c|c|c|c|}
\hline & \multicolumn{3}{|c|}{$\begin{array}{l}\text { No of patients with serum potassium } \\
\leqslant 3.5 \text { mmolll }\end{array}$} & \multicolumn{3}{|c|}{$\begin{array}{l}\text { No of patients with serum potassium } \\
\geqslant 3.6 \mathrm{mmol} / \mathrm{l}\end{array}$} \\
\hline & Total & Men & Women & Total & Men & Women \\
\hline $\begin{array}{l}\text { All patients with ventricular fibrillation } \\
\text { No of deaths (\%) }\end{array}$ & $21(33)$ & $\begin{array}{r}12 \\
3\end{array}$ & $\begin{array}{l}9 \\
4\end{array}$ & 71 & $\begin{array}{l}56 \\
23\end{array}$ & $\begin{array}{r}15 \\
8\end{array}$ \\
\hline
\end{tabular}

Table 4 Percentage of patients receiving drug treatment before admission

\begin{tabular}{llll}
\hline $\begin{array}{l}\text { Treatment before } \\
\text { admission }\end{array}$ & $\begin{array}{l}\text { \% patients with } \\
\text { serum potassium } \\
\leqslant 3.5 \text { mmoll } \\
(n=122)\end{array}$ & $\begin{array}{l}\text { \% patients with } \\
\text { serum potassium } \\
(n .6 \text { mmolll } \\
(n=952)\end{array}$ & $p$ \\
\hline Diuretics & 55 & 22 & $<0.01$ \\
Digitalis & 9 & 19 & $<0.01$ \\
\hline
\end{tabular}

In the 1074 patients hypokalaemia was related to diuretic treatment before admission; digitalis treatment was more common in the normokalaemic group (Table 4). Mean serum potassium concentration for the 982 patients who did not develop ventricular fibrillation was $4.1 \mathrm{mmol} / \mathrm{l}$ and $3.9 \mathrm{mmol} / \mathrm{l}$ for the 92 patients who did develop ventricular fibrillation $(\mathrm{p}<0.05)$.

Twelve patients (four hypokalaemic and eight normokalaemic) had ventricular fibrillation on admission but survived long enough to fulfill diagnostic criteria for inclusion in the study. The mean plasma $\mathrm{pH}$ for these patients was $7 \cdot 37$ (range $7 \cdot 28-7 \cdot 44$ ). The mean standard bicarbonate concentration was $25.5 \mathrm{mmol} / \mathrm{l}$ (range $18-30 \mathrm{mmol} / \mathrm{l}$ ). None of these patients became alkalotic after sodium bicarbonate infusion during resuscitation before blood was drawn for serum potassium estimation. The potassium values obtained were therefore accepted as indicative of the concentration before the onset of ventricular fibrillation. There was, however, a significant difference in the incidence of ventricular fibrillation between the hypokalaemic and normokalaemic groups even if these 12 patients are excluded $(14 \% v 7 \% ; \mathrm{p}<0.02)$.

\section{Discussion}

This study shows a substantial significantly greater incidence of ventricular fibrillation in patients with acute myocardial infarction who were hypokalaemic on admission to hospital. This could not be explained by a greater number of patients with large infarcts and a bad prognosis in the hypokalaemia group. Digitalis is arrhythmogenic in hypokalaemic patients with chronic heart failure, ${ }^{11}$ but no association between digitalis treatment, hypokalaemia, and ventricular fibrillation was found (Table 2 and 4).
In the 1074 patients hypokalaemia was related to diuretic treatment (Table 4), the relation being less obvious in patients with ventricular fibrillation (Table 2), of whom $62 \%$ of those with hypokalaemia were not taking diuretics. This hypokalaemia did not result from treatment with insulin, steroids, or antibiotics and could not be explained by other diseases associated with hypokalaemia. ${ }^{9}$

Hypokalaemia has been reported to be more common in women than in men. ${ }^{69}$ The incidence of hypokalaemia in all our patients was $17 \%$ for women and $9 \%$ for men (Table 1 ), and for those with ventricular fibrillation 9 of 24 women (38\%) and 12 of 68 men $(18 \%)$ were hypokalaemic. Thus overall the incidence of hypokalaemia was significantly higher in women than in men for both groups of patients. Among the 1074 patients women were significantly older than men, but hypokalaemia was not related to age in this population of patients below 76 years.

Raised concentrations of catecholamines have been suggested as a possible cause of transient initial hypokalaemia in patients with acute myocardial infarction, ${ }^{12}$ but it remains to be shown if this can explain the preponderance of women with low serum potassium values.

There was an early occurrence of ventricular fibrillation in the low serum potassium group. This finding and the absence of lung congestion on the initial clinical examination may indicate that there were more patients with primary ventricular fibrillation in the hypokalaemic group, as primary ventricular fibrillation occurs earlier during the acute infarction than secondary (complicating) ventricular fibrillation. ${ }^{8}$

The frequency of treatment with frusemide for heart failure (Table 2) was not significantly different between the groups during the first week. By the end of the first week there was less lung congestion in the hypokalaemic group as shown on the chest $x$ ray film, and thus the degree of heart failure seems to have been less severe in the hypokalaemic group.

Subgrouping of hypokalaemic and normokalaemic patients with ventricular fibrillation according to the early occurrence of ventricular fibrillation after admission ${ }^{24}$ may not give a correct comparison of the true incidence of ventricular fibrillation in the two groups. Such subgrouping brings in time as a variable 
between the two groups and favours the incidence of ventricular fibrillation in the hypokalaemia group, as ventricular fibrillation tended to occur later in the normokalaemic group.

Only initial potassium values were used in this study so that patients could be divided into groups according to potassium values estimated at a similar time-that is, the start of hospital treatment of the infarction, which in this study was also comparable in the number of hours from the onset of the acute myocardial infarction. Some reports ${ }^{25}$ have divided patients into groups according to potassium concentrations obtained around the time of the ventricular fibrillation and potassium concentrations obtained on admission for patients without ventricular fibrillation. This is likely to give a falsely high incidence of ventricular fibrillation in the hypokalaemic group as a fall in serum potassium resulting from diuretic treatment after admission will be observed only in patients with ventricular fibrillation. It is also likely to accumulate patients in need of diuretic treatment with bad left ventricular function, and therefore a high risk of arrhythmias, into the hypokalaemic group.

We conclude that hypokalaemia on admission to hospital predicts an increased incidence and early occurrence of ventricular fibrillation in patients with acute myocardial infarction. A causative role of hypokalaemia is more difficult to establish, however, without showing a decrease in ventricular fibrillation resulting from potassium correction.

\section{References}

1 Duke M. Thiazide-induced hypokalemia. Association with acute myocardial infarction and ventricular fibrillation. FAMA 1978; 239: 43-5
2 Hulting J. In-hospital ventricular fibrillation and its relation to serum potassium. Acta Med Scand 1981; suppl 647: 109-16.

3 Donnelly T, Gray H, Simpson E, Rodger JC. Serum potassium in acute myocardial infarction [Abstract]. Scott Med F 1980; 25: 176.

4 Bech OA, Hochrein H. Serumkaliumspiegel und Herzrhythmusstörungen beim akuten Myocardinfarkt. $Z$ Kardiol 1977; 66: 187-90.

5 Solomon RJ, Cole AG. Importance of potassium in patients with acute myocardial infarction. Acta Med Scand 1981; suppl 647: 87-93.

6 Dyckner T, Helmers C, Lundman T, Wester PO. Initial serum potassium level in relation to early complications and prognosis in patients with acute myocardial infarction. Acta Med Scand 1975; 197: 207-10.

7 The Norwegian Multicenter Study Group. Timololinduced reduction in mortality and reinfarction in patients surviving acute myocardial infarction. $N$ Engl $\mathcal{F}$ Med 1981; 304: 801-7.

8 Lawrie DM, Higgins MR, Godman MJ, Oliver MF, Julian DG, Donald KW. Ventricular fibrillation complicating acute myocardial infarction. Lancet 1968; ii: 523-8.

9 Lawson DH, Henry DA, Lowe JM, Gray JMB, Morgan HG. Severe hypokalemia in hospitălized patients. Arch Intern Med 1979; 139: 978-80.

10 Grizzle JE, Starmer CF, Koch GG. Analysis of categorical data by linear models. Biometrics 1969; 25: 489-504.

11 Steiness E, Olesen KH. Cardiac arrhythmias induced by hypokalaemia and potassium loss during maintenance digoxin therapy. $\mathrm{Br}$ Heart $\mathcal{F}$ 1976; 38: 167-72.

12 Struthers AD, Reid JL, Whitesmith R, Rodger JC. Effect of intravenous adrenaline on electrocardiogram, blood pressure, and serum potassium. Br Heart $\mathcal{F}$ 1983; 49: $90-3$.

Requests for reprints to: Dr J E Nordrehaug, Department of Medicine, Diakonissehjemmets Sykehus, Haraldsplass, 5000 Bergen, Norway. 